\title{
3-Dimensional Ultrasound Mode
}

National Cancer Institute

\section{Source}

National Cancer Institute. 3-Dimensional Ultrasound Mode. NCI Thesaurus. Code C130060.

A method of ultrasound imaging that allows for the construction of three dimensional images of a given object/structure. 